\title{
Use of transcutaneous capnography in critically ILL patients
}

\author{
G Morales Varas*, H Marin Mateos, S Chancón Alves, M Castillo Jaramillo, JA Sánchez-Izquierdo Riera, \\ JC Montejo González \\ From ESICM LIVES 2015 \\ Berlin, Germany. 3-7 October 2015
}

\section{Introduction}

Assess alveolar ventilation is a routine when patients are mechanically ventilated. Transdermal devices that measure $\mathrm{CO}_{2}$ pressure $\left(\mathrm{PtcCO}_{2}\right)$ are can be used but should be evaluated in critically ill patients with altered tissue perfusion.

\section{Objectives}

To determine the usefulness of transcutaneous capnography in patients with mechanical ventilation.

\section{Methods}

A prospective-observational, single-center study was carried out in the medical-surgical intensive care unit (ICU) at university hospital. Population: All patients over 16 years old, who required respiratory support with invasive mechanical ventilation, the measurement of PtcC02 is done by SenTec Digital Monitor and their results were compared with samples of blood gas analysis (PaC02) in patients with different hemodynamic conditions. Study period: June 2014 to December 2014. Demographic and clinical date included reason for admission, body temperature, requirement of vasoactive drugs, neuromuscular blockers and maneuvers using for treat to the refractory hypoxemia such as prone position ventilation and veno-venous extracorporeal membrane oxygenation (ECMOv-v). Statistical analysis of the results was performed using SPSS software version 22 . Quantitative variables were expressed as mean and SD. Qualitative variables were expressed as percentages. Agreement between $\mathrm{PaC0} 2$ and PtcC02 was evaluated using lineal regression analysis.

\section{Results}

A total of 78 samples were analyzed. Mean age was 58 (SD 9.9) years, with an average stay in ICU of 24.8 (SD 13.3) days, the main reason for admission was respiratory distress syndrome (ARDS) with $42.3 \%$ of the patients, $24.3 \%$ of them were ventilated in prone position and $48.4 \%$ received support with ECMO v-v. Mean of PtcC02 vs $\mathrm{PaC0} 2$ was 54.2 (SD 11.2) $\mathrm{mmHg} / 55.4$ (SD 12.8) $\mathrm{mmHg}$ respectively. PtcC02 was highly correlated with $\mathrm{PaC0} 2(\mathrm{r}=$ $0.79 ; \mathrm{p}<0.001$ ), as determined to by lineal regression analysis. $37.2 \%$ of the samples under support with vasoactive drugs did not affect PtcC02 accuracy $(\mathrm{r}=0.75 ; \mathrm{p}<0.001)$ relative to the $\mathrm{PaCO} 2$.

\section{Conclusions}

In our study, continuous monitoring of the trends of PtcC02 constitutes an useful method for assessing alveolar ventilation in critically ill mechanically ventilated even in situations of hemodynamic inestability.

Published: 1 October 2015

\section{References}

1. Rodriguez P, Lellouche F, Aboab J, Buisson CB, Brochard L: Transcutaneous arterial carbon dioxide pressure monitoring in critically ill adult patients. Intensive Care Med 2006, 32(2):309-12, Feb.

2. W Baulig, RR Roediger, O Theusinger, Rusch D, Spahn D: Combined oximetry and transcutaneous capnography is a reliable non-invasive monitoring in patients after cardiac surgery. Critical Care 2010, 14(Suppl 1):P168.

3. SenTec Digital Monitor: Mode d'emploi Therwil, Suisse; 2002.

doi:10.1186/2197-425X-3-S1-A389

Cite this article as: Morales Varas et al:: Use of transcutaneous

capnography in critically ILL patients. Intensive Care Medicine Experimental 2015 3(Suppl 1):A389. 